\title{
ISOLATION OF PLANT PARASITIC NEMATODES IN PEAR ORCHARD AT CHHAIMALE (PHARPING) VDC OF KATHMADU
}

\author{
Shrestha, R . ${ }^{1}$ and Bam, A .B. ${ }^{2}$ \\ 1- Ramila shrestha, Central Department of zoology, T.U, Kirtipur, Sthrami669@gmail.com \\ 2- Ashok Bahadur Bam, Central Department of zoology, T.U, Kirtipur, ashokbam@gmail.com
}

\begin{abstract}
Plant-parasitic nematodes are of considerable importance worldwide and their devastating effects on crops have major economic and social impacts. They depend on plants and feed on all parts of the plant including roots, stems, leaves, flowers and seeds. The majority of species of plant-parasitic nematodes live on or around plant roots. Nematode damage of the plant's root system also provides an opportunity for other plant pathogens to invade the root and thus further weakens the plant. A study was carried out to isolate and identify different genera of plant parasitic nematodes from the rhizospheres of pear plants in one of the major pear producing area of Nepal, Chhaimale VDC of Kathmandu district.

Altogether seven species of root nematodes were isolated from soil samples collected: Tylenchorhynchus sp., Longidorus sp., Helicotylenchus sp., Hoplolaimus sp., Aphelenchus sp., Mononchus sp. and Diplogaster sp. Among isolated species of nematodes Tylenchorhynchus sp., Longidorus sp., Helicotylenchus sp., and Hoplolaimus sp. are parasitic, Aphelenchus sp. is mycophagic and Mononchus sp. and Diplogaster sp. are predatory in nature. Number of nematodes were not significantly different in different season and at different locations.
\end{abstract}

Keywords: Isolation, Root nematodes, Pear

\section{Introduction}

Nematodes (nema= thread in Gr.) are pseudocoelomate, unsegmented worm-like animals, commonly described as filiform or thread-like. At present, nematodes are generally regarded as a separate phylum, the Nematoda or Nemata (De Ley and Blaxter, 2004). They are either free-living or parasites of plants and animals. Of the known nematode species, approximately $50 \%$ are free-living species found in soil or freshwater, 25\% are marine (found in sea water), 15\% are animal parasites, and 10\% are known plant parasitic nematodes (Pokharel and Larsen, 2007). Nematodes have evolved to fill almost every conceivable niche on earth that contains some amount of water. They are highly diverse. There are a number of plant parasitic nematodes which depend of root system of plants for feeding. The feeding system damages the plant's root system and reduces the ability to absorb water and nutrients. Typical nematode damage symptoms are a reduction of root mass, a distortion of root structure and/or enlargement of the roots. Nematode damage of the plant's root system also provides an opportunity for other plant pathogens to invade the root and thus further weakens the plant. The aboveground symptoms of nematode damage to roots are relatively nondescript, including nutrient deficiency, incipient wilt, stunting, poor yield and sometimes plant death (Lambert and Bekal, 2002).

There are a lot of nematodes parasitic to fruit plants, there is certainly a considerable number of nematodes parasitic to pear plants. These nematodes attack different parts of plant and lowers the production significantly if infested heavily and thus is a limiting factor to production. In order to constrain or even banish this limiting factor in agricultural production, it is vital to identify accurately the nematode pests and to understand their biology. This information may useful to control them and consequently

Nepalese Journal of Zoology | Online Volume 3 Issue 1 | November 2015 | Page 76 
increase production. There have been a number of studies done of the nematode diversity of different parts of Nepal but no work has been carried out to study the nematodes associated with pear plants. Present study is thus first of its kind. Present study was thus focused to study the prevalence of nematodes in pear orchards of Chhaimale VDC of Kathmandu district which is a pocket area of pear production in Nepal.

The variety of pear grown in this area is Sand Pear (Pyrus pyrifolia) commonly called as Pharping Naspati in Nepali. It is a suitable variety to be cultivated as cash crop in Nepal and Himalayan states of India. It can be cultivated in mid hills between about 1500 and 2500 meters above sea level. This variety needs comparatively low chilling hours ( $<1000$ hours) and are well adapted in warmer temperate region of Nepal.

\section{Materials and Methods}

Present study was carried out in Chhaimale VDC which is the southern most VDC of Kathmandu district. The main agricultural crops in this VDC are maize and millet while major horticultural product are Pear, Cucumber, oil seed, vegetables and Peach. The sample collection was carried out for 6 months divided into two seasons. First study was carried out in summer from March 2012 to May 2012 and second study was carried out in autumn from August 2012 to October 2012.

Soil samples were collected from the rhizosphere of 30 mature pear plants selected randomly at study site with 6 samples from each ward. The soil sample was collected from the rhizosphere of each selected plant from nearly to five feet away from the main trunk of the tree and about $20-30 \mathrm{~cm}$ below the surface of the soil. The soil was dug by iron rod and hole was made. From this hole about $30 \mathrm{~cm}$ depth, about 500 gm of soil with rhizosphere was collected in polythene bag. The samples were analyzed for presence of parasitic and non-parasitic nematodes. The collected soil samples were processed by Cobb's (1918) modified sieving and decantation technique followed by Baermann funnel technique (Baermann, 1917). For the processing and fixation of collected samples of nematodes mainly two chemicals were used prepared in laboratory. The chemicals used were TAF solution for fixation and Glycerol- ethanol solution for processing. Permanent slides were prepared from the nematodes collected by fixation and collection. The slides were observed under the low power and high power magnification (i.e. 10x, 20x and 40x) and the characters were compared with the taxonomy key of Mai and Lyon, 1975 and arranged by Baldwin , 1990. Data analysis was done using Chi-square test and ANOVA with the help of SPSS V 16.0.

\section{Result and Discussion}

\section{Nematode Prevalence}

Preparation of permanent sample was done from randomly sampled nematodes one from each sample. Thus, altogether 60 samples of nematodes were studied by preparing slides from the rhizosphere collected from study site among which 30 were from summer and 30 from autumn. Prevalence of different nematode species collected during study period in two seasons is shown in table 1.

Table 1: Nematode species identified in two seasons in pear plants of Chhaimmale

\begin{tabular}{|l|l|l|l|l|l|}
\hline $\begin{array}{l}\text { S. } \\
\text { No }\end{array}$ & Nematodes species & $\begin{array}{l}\text { Number in } \\
\text { summer sample }\end{array}$ & Percentage & $\begin{array}{l}\text { Number in } \\
\text { autumn sample }\end{array}$ & Percentage \\
\hline 1 & Tylenchorhynchus $s p$. & 12 & 40.00 & 6 & 20.00 \\
\hline 2 & Longidorus $s p$. & 5 & 16.67 & 7 & 23.33 \\
\hline 3 & Helicotylenchus $s p$. & 7 & 23.33 & 4 & 13.33 \\
\hline
\end{tabular}

Nepalese Journal of Zoology| Online Volume 3 Issue 1 | November 2015 | Page 77 


\begin{tabular}{|l|l|l|l|l|l|}
4 & Hoplolaimus $s p$. & 1 & 3.33 & 3 & 10.00 \\
\hline 5 & Aphelenchus $s p$. & 1 & 3.33 & 2 & 6.67 \\
\hline 6 & Mononchus $s p$. & 3 & 10.00 & 7 & 23.33 \\
\hline 7 & Diplogaster $s p$. & 1 & 3.33 & 1 & 3.33 \\
\hline & Total & 30 & 100 & 30 & 100 \\
\hline
\end{tabular}

There was significant difference $\left(\chi_{\text {cal }}^{2}>\chi_{\text {tab }}^{2}\right)$ between the total number of nematode species in samples studied in summer. In summer, number of Tylenchorhynchus sp. was highest (40\%) followed by Helicotylenchus sp. (23.3\%), Longidurus sp. (16.7\%), Mononchus sp. (10\%) and Hoplolaimus sp. (3.3\%), Aphelenchus sp. (3.3\%) and Diplogaster sp. (3.3\%). in as compared to other species. Whereas total number of different species of nematodes in soil samples collected in autumn also showed no significant difference $\left(\chi_{\text {cal }}^{2}<\chi_{\text {tab }}^{2}\right)$.

There was significant difference $\left(\chi_{\text {cal }}^{2}>\chi^{2}\right.$ tab $)$ among the total number of soil nematodes studied in slides in both seasons Tylenchorhynchus sp. which is a plant parasitic nematode was recorded in highest number (30\%) followed by Longidurus sp. (20\%), Helicotylenchus sp. (18\%), Mononchus sp. (17\%), Hoplolaimus sp. (7\%), Aphelenchus sp. (5\%) and Diplogaster sp. (3\%) in lowest number which is a free living nematode.

Different species of Tylencorhynchus were found to be parasitic on different types of plants (McSorley, 2013; Zaaki and Mantoo, 2003; Ismail et al., 2002; Upreti, 2000; Pokharel and Regmi, 2000; Golden et al., 1987). Upreti (2000) and Pokharel and Regmi (2000) have recorded Tylencorhynchus sp. in rice and wheat crops of lowland as well as uplands of Nepal. Zaki and Mantoo (2003) have recorded

Tylencorhynchus sp. in different fruit trees (Cherry, Walnut, Apple, Apricot, Plum and Pear) in Kashmir valley alongwith other 9 parasitic species of nematodes. Though this nematode is recorded in cereal crops in Nepal, no record of Tylencorhynchus sp. in fruit trees of Nepal has been found yet. Thus, this may be the first record of Tylencorhynchus sp. in fruit trees in Nepal. Longidorus sp. also known as needle nematodes are also reported to affect trees as they are responsible for severe decline symptoms in trees (Hashim, 1983) when infested heavily. No record of Longidorus sp. has been reported in Nepal. ). Present study recorded relatively higher infestation of Longidorus sp. in pear tree rhizosphere in summer as well autumn samples. Pokharel and Regmi (2000) and Upreti (2000) have reported this species from rice and wheat fields in Nepal but no report of this genera have been found so far in trees, thus, this may be first report of Helicotylenchus sp. in peer trees in Nepal. Pokharel and Regmi (2000) and Upreti (2000) have recorded Hoplolaimus from fields with rice and wheat crop systems in Nepal while McSorley (2013) reported that this species is prominent in forest as compared to fields. This study also found Hoplolaimus sp. in rhizosphere of pear trees in both summer and autumn season but in comparatively lower density.

Aphelenchus species are common soil inhabiting nematode feeding on fungi (Barker and Darling, 1965). Aphelenchus avenae have been used successfully as a potential biological control agent for root rot fungi (Barnes et al., 1981). These nematodes may be beneficial rather than harmful if they are of mycophagic species. A detail study at species level is necessary to know about the species and its economic importance. Mononchus nematodes are non-parasitic predatory nematodes that feed on protists as well as other small nematodes (Mankau and Mankau, 1963). There are no records of occurrence of Mononchus sp. in cultivated plants in Nepal thus, this may be first report about occurrence of Mononchus sp. in cultivated fruit tree in Nepal. Diplogaster sp. are one of the less studied predaceous nematodes which may

Nepalese Journal of Zoology | Online Volume 3 Issue 1 | November 2015 | Page 78 
be beneficial to cultivars. Present study also identified Diplogaster sp. from the specimens collected. This shows that Diplogaster species may be present there for predation on other species of nematodes present in rhizosphere of pear.

\section{Prevalence of nematodes in different wards}

There were six samples collected from each of 5 wards in study area in both summer and autumn season. Number of nematodes found in samples of $500 \mathrm{gm}$ soil from each site in both seasons is shown in figure 1.

There was no significant difference $(P>0.05)$ in number of soil nematodes in samples collected from pear orchards of different wards in Chhaimale in summer season. Similarly, there was no significant difference $(P>0.05)$ in number of soil nematodes per $500 \mathrm{gm}$ sample from different wards during autumn season among different wards in Chhaimale VDC. Figure 2 shows the average number of nematodes per $500 \mathrm{gm}$ soil sample in two seasons in different wards of study area.

Present study found that number of nematodes per 500 gm soil sample ranged from 4-19 with an average

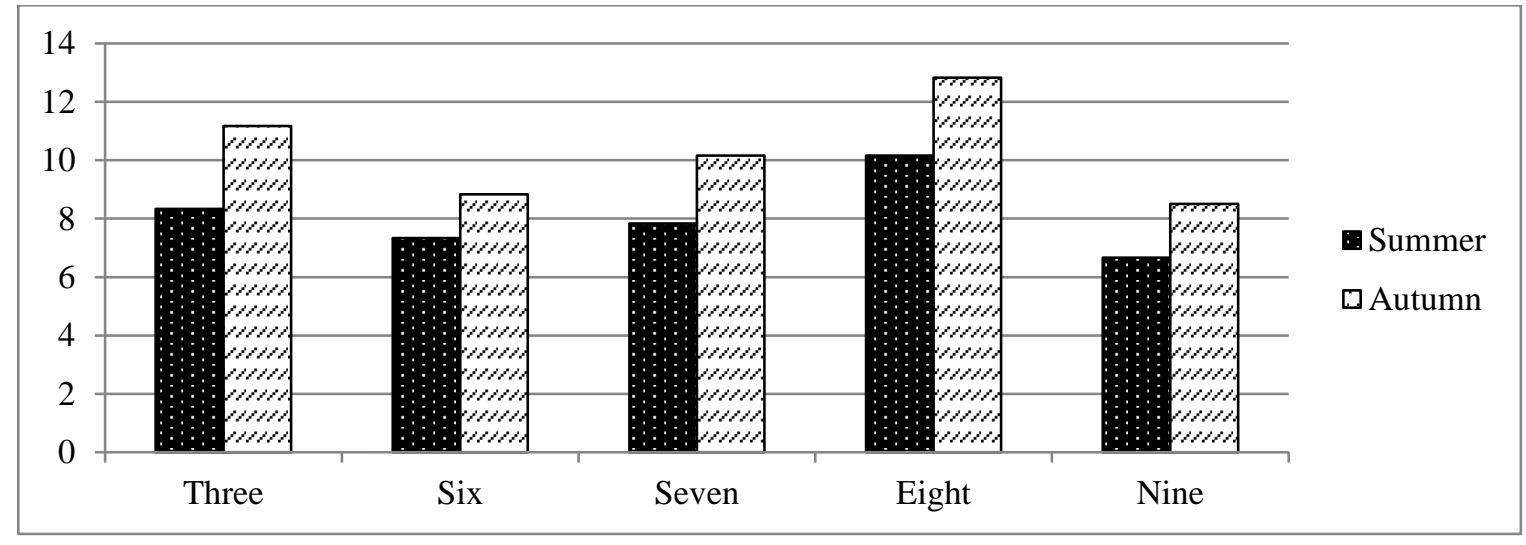

Figure 2: Average number of soil nematodes found in soil samples of different wards in two seasons

of $9.18 \pm 1.54$. Aksary et al. (2011) reported that at least 30 nematodes/100gm soil may cause any significant suppress in growth of plant. Some nematodes may cause a damage only when they are present in a larger number i.e. upto 5000 nematodes/100gm soil. Compared with these data, number of nematodes recorded in soil of present study may not be able to cause any significant damage to pear plants. Also, the presence of predaceous nematodes such as Mononchus and Diplogaster may be account for relatively lower density of nematodes in rhizosphere of pear plants.

\section{Conclusion}

Diversity of nematodes in rhizosphere of pear plants from the pear orchards in Chhaimale VDC of Kathmandu have been studied. Altogether 7 species of nematodes have been recorded during study period of two seasons: Summer and Autumn of 2012. Seven species recorded during study were :

Tylencorhynchus, Longidorus, Helicotylenchus, Hoplolaimus, Aphelenchus, Mononchus and Diplogaster. Among the recorded species Tylencorhynchu,Longidorus, Helicotylenchus and Hoplolaimus are parasitic in nature either endoparasite, semi-endoparastite or ectoparasite while Aphelenchus is a mycophagic nematode feeding on fungi and Mononchus and Diplogaster are predatory an a wide range of micro- 
organisms including some nematodes also. There was no significant difference in occurrence of nematodes in two seasons: summer (pre-monsoon) and autumn (post-monsoon). Number of Tylencorhynchus was significantly higher in summer as compared to other nematodes while in autumn occurrence of Longidorus and Mononchus was higher relatively. In overall, number of Tylencorhynchus was highest in all sites and Diplogaster was lowest. Present study found that number of nematodes per $500 \mathrm{gm}$ soil sample ranged from 4-19 with an average of 9.18 \pm 1.54 . There was no significant difference in number of soil nematodes in samples collected from pear orchards of different wards in Chhaimale during whole study period.

\section{Acknowledgements}

We would like to express our sincere gratitude to Head of the Department Prof. Ranjana Gupta and Central Department of Zoology, Kirtipur for providing a chance to carry out this research and for providing laboratory facilities and equipments. We would like to express our sincere thanks to Prof. Arvind kumar Keshari, Associate Prof. Dr. Mahendra Maharjan, Central Department of Zoology and Dr. Suraj Baidhaya, NARC, Khumaltar, for the continuous guidance, critical suggestions, regular inspiration and deep concern throughout the field work without the help of whom this research work could not have been carried out successfully. Finally we would like to appreciate all our friends and colleagues who cooperated during all the works of this research work.

\section{References}

Baerman, G. 1917. Eine einsache method zur auffindung von ankylostomum (Nematodin) larven in erdproben. Genee Sk. Tijdschr. Ned. Indie. 57:131-137

Cobb, N. A. 1918. New nematode genera found inhabiting fresh-water and non-brackish soils. Journal of the Washington Academy of Sciences 3:432-445.

De Ley, P. and Blaxter, M. L. 2004. A new system for Nematoda: combining morphological characters with molecular trees, and translating clades into ranks and taxa.In: Cook, R. \& Hunt, D.J. (Eds.), Proceedings of the Fourth International Congress of Nematology, 8-13 June 2002, Tenerife, Spain. Nematology Monographs and Perspectives 2. Brill, Leiden, The Netherlands: 633-653.

Golden, A. M., Maqbool, M .A. and Zafar, A. H. 1987. Descriptions of Two New Species of Tylenchorhynchus Cobb, 1913 (Nematoda: Tylenchida), with Details on Morphology and Variation of 7". claytoni 1. Journal of Nematology 19(1):58-68.

Hashim, Z. 1983. Plant-parasitic nematodes associated with pomegranate (Punica granatum L.) in Jordan and an attempt to chemical control. Nematologia Mediterranea, 11: 199-200.

Lambert, K. and Bekal, S. 2002. Introduction to Plant-Parasitic Nematodes. The plant health instructor. DOI: 10.1094/PHI-I-2002-1218-01. Accessed from www.apsnet.org/educenter/intropp/PathogenGroups/Pages/IntroNematodes.aspx

Mai W. F. and H. H. Lyon (1975). Pictorial Key to Genera of Plant Parasitic Nematodes. Cornel University Press, Ithaca, NY, 219 pp.

Mankau, R. and Mankau, S. K. 1963. The role of mycophagous nematodes in the soil. I. The relationships of Aphelenchus avenae to phytopathogenic soil fungi.In: Soil Organisms. Eds. J. Doeksen and J. van der Drift. North Holland, Amsterdam, The Netherlands: 271-280.

Nepalese Journal of Zoology | Online Volume 3 Issue 1 | November 2015 | Page 80 
MCSorley, R. 2013. Effect of forest and field habitat features on abundance of genera in nematode assemblages. Nematology, 15: 947-95

Pokharel, R. P. and Regmi, A. P. 2000. Distribution and management of rice root nematodes in rice-based cropping systems in Rupandehi district of Nepal.: proceedings of review and planning meeting and training workshop, 5-10 April 1999, Division of Nematology, Indian Agricultural Research Institute, New Delhi, India (Sharma, S.B., Pankaj, Pande, S., and Johansen, C., eds.). Rice-Wheat Consortium Paper Series 7. New Delhi, India: Rice-Wheat Consortium for the Indo-Gangetic Plains, and Patancheru 502 324, Andhra Pradesh, India: International Crops Research Institute for the Semi-Arid Tropics: 29-30

Pokharel, R. R. and Larsen, H. J. 2007. The importance and management of phytoparasitic nematodes in western Colorado fruit orchards. Journal of Nematology 39(1): 96.

Upreti, R.P. 2000. Nematodes associated with rice-wheat-legume cropping systems in Nepal. Proceedings of review and planning meeting and training workshop, 5-10 April 1999, Division of Nematology, Indian Agricultural Research Institute, New Delhi, India (Sharma, S.B., Pankaj, Pande, S., and Johansen, C., eds.). Rice-Wheat Consortium Paper Series 7. New Delhi, India: Rice-Wheat Consortium for the Indo-Gangetic Plains, and Patancheru 502 324, Andhra Pradesh, India: International Crops Research Institute for the Semi-Arid Tropics: 31-32.

Zaki, F. A. and Mantoo, M. A. 2003. Plant parasitic nematodes associated with temperate fruits in Kashmir valley, India. Pest Management and Economic Zoology, 11(1): 97-101.

Nepalese Journal of Zoology | Online Volume 3 Issue 1 | November 2015 | Page 81 